Article

\title{
Sustaining Students' Identities within the Context of Participatory Culture. Designing, Implementing and Evaluating an Interactive Learning Activity
}

\author{
Moisès Esteban-Guitart *(D), Pilar Monreal-Bosch, Montserrat Palma and Irene González-Ceballos \\ Department of Psychology, Institute of Educational Research, University of Girona, Pl. Sant Domènec, \\ 9, 17004 Girona, Spain; pilar.monreal@udg.edu (P.M.-B.); montserrat.palma@udg.edu (M.P.); \\ irene97gonzalez@gmail.com (I.G.-C.) \\ * Correspondence: moises.esteban@udg.edu; Tel.: +34-630-278-656
}

Received: 29 March 2020; Accepted: 12 June 2020; Published: 15 June 2020

check for updates

\begin{abstract}
Within the framework of theoretical developments in so-called participatory culture and the context of funds of identity, incorporated within what is known as the funds of knowledge approach, an innovative teaching methodology is implemented that allows students to actively participate in knowledge construction. The project translates into a proposal for educational contextualization and personalization, based on the students' funds of identity; that is, those resources (people, artifacts, places, activities, institutions) they consider to be most relevant and significant to defining themselves. Once these have been identified through identity artifacts, such as collages or self-drawings, students link some of these funds of identity to curricular content of the subject and produce a video that shows the results of this academic work. The final product is shared on a YouTube channel containing the videos of all of the students in the class. The phases of the project are described and illustrated. We argue that the proposed teaching and learning project, which is cross-disciplinary in nature, allows for principles such as educational contextualization, funds of identity and participatory culture to be incorporated into what we call here the funds of identity 2.0 approach, putting it into educational practice.
\end{abstract}

Keywords: funds of identity; funds of knowledge; active methodologies; contextualization; personalized learning; participatory culture; culturally sustaining pedagogy

\section{Introduction}

In recent decades, digital media has facilitated the emergence of new ways of creating, sharing and organizing knowledge, often unknown of and ignored by schools and the formal contexts of teaching and learning [1-6]. Many of these digital practices revolve around popular youth culture, and take the form of affiliations in online communities such as Facebook, expressions such as creating videos, multimodal and transmedial forms of writing, collaborative problem-solving to complete tasks-including certain collaborative video games—or developing new shared knowledge, such as Wikipedia, as well as the dissemination of content in a blog, etc. [7-12].

Indeed, educational practices have been transformed by digital media into active methodologies that allow the student to have an active role in the learning processes, interacting with peers and technologies over time $[13,14]$. In particular, social online networking communities can be considered a public space for socialization, interaction, creation, and diffusion of culture and identity; a place where people can participate, learn, and bring about social transformation $[4,15,16]$. In this context, the term participatory culture refers to new ways in which the cultural product or media, and the consumer or user, relate to one another as a result of the emergence of Web 2.0. technologies [11,12]. 
The result of this is the emergence of cultural practices characterized by low barriers to learning, artistic expression or civic engagement. These digital practices are based on creating and sharing experiences, and appropriating and recirculating media content fueled by peoples' interest [17,18]. In that regard, by participatory culture we mean: "a culture in which large numbers of people from all walks of life have the capacity to produce and share media with each other, often responding critically to the products of mass media, and often circulating what they create fluidly across a range of different niche publics", [19] p. 3.

In other words, people are no longer merely observers of what is happening on television, on the computer, on the tablet or on the game console; rather, we are able to participate in the production of cultural contents and practices. In fact, more than half of teens and young people have created digital media content (YouTube videos or Wikipedia entries, for example), and a third of internet users have shared content that they themselves have produced via blogs, Facebook, YouTube, etc. [20]. In some cases, people are actively involved in processes of cultural participation, such as in the amateur design of a video game, movie, or song, often close in quality to that of a professional production. Thus, the notion of participatory culture can be considered both a description of digital cultures in a hyper-connected society - which revolves around movements and transactions [16] - and a desire or aspiration centered on accessible and public forms of cultural production and sharing [17].

\section{Funds of Knowledge, Funds of Identity and Funds of Identity 2.0}

The idea of funds of identity emerges within the context of the funds of knowledge approach, which attempts to contextualize the curriculum on the basis of using, for pedagogical purposes, the skills and abilities that all families have, regardless of their economic, social and cultural status [21-23]. In this respect, funds of knowledge are understood as: "Culturally developed and historically accumulated bodies of knowledge, together with essential skills for the functioning and well-being of families and individuals", [24] p. 47. Broadly, what we mean by contextualization, teaching in context, or culturally congruent teaching is: "connecting teaching and curriculum to experiences and skills of students' home and community", [25] p. 11. In other words, educational contextualization refers to the integration of academic concepts, topics or competences with students' personal, home and community learning experiences [26].

The funds of knowledge approach is an inclusive perspective, that seeks to challenge the negativity of deficit thinking through positive recognition of students' families. Deficit thinking in education arises from an unfounded perception that students of foreign origin, or from minorities, fail at school because of deficiencies in their families-such as a lack of cultural resources, inadequate home socialization or limited intelligence-which obstruct the students' learning process [27]. In contrast, the funds of knowledge approach maintains that families of foreign origin accumulate particular skills and intellectual expertise that make them unique and valuable. In that regard, it is implicitly assumed that all households possess resources, abilities and bodies of knowledge, regardless of their ethnic, economic or linguistic background [21]. The challenge is to link these funds of knowledge creatively with the curriculum and school practice, in order to improve learning [28]. In practice, this translates into forming a distinct community of practice, or a study group, composed of different teachers and university researchers [29], as well as ethnographic visits by teachers to the homes of some of their students, in order to identify their funds of knowledge and establish ties of mutual trust between the school and the families. Once these skills and knowledges have been identified, they are linked to curricular content, using educational innovations based on local knowledge and the previously identified skills of the families [22,30,31]. For example, a natural science teacher in a primary school used one father's occupation in agriculture (i.e., breeding and taking care of animals on a farm) to develop learning objectives such as classifying animals according to what they eat (herbivores, carnivores, omnivores) [32].

However, there are certain constraints and limitations to the funds of knowledge approach that can make it difficult to put it into practice, and which can reduce its efficacy. With the funds of 
knowledge approach, teachers need time, space and supportive networks to arrive at an understanding of the complexity of sociocultural practices, families' lived experiences, students' identities and their particular learning processes. Subsequently, putting this understanding of the families' knowledges, resources and contexts into pedagogical action is not an easy task [33]. Three problems in particular have been identified [30,31,34]: (i) Implementing this approach requires time. Teachers cannot visit all of their students' homes. In any given classroom, only a limited number of the students and their families can be focused on. (ii) There is a lack of specific focus on the learner, while so much attention is on the family and their knowledge and abilities. Within a single family, there are some discontinuities in the shared funds of knowledge, which means learners might not necessarily share some of the funds of knowledge gained by their parents or significant adults. Moreover, learners, as socially active agents, build and acquire their own funds of knowledge, distinct from those of their families, based on their own experiences, abilities and interests. As these funds build up, it becomes necessary to incorporate them into the equation together with the family funds of knowledge. (iii) Finally, there is a methodological limitation. In short, in order to identify students' funds of knowledge, teachers carry out open interviews in the context of household visits, which generally means in-depth interviews are used, whereas it has been shown that other qualitative strategies are possible, such as projective techniques (i.e., identity drawings) [35].

In order to overcome these limitations, the concept of funds of identity has recently been suggested [36-38]. This concept places the emphasis on students' interests, practices and experiences through the incorporation of creative works—referred to as identity artifacts [39] — made by the learners themselves, which then become educational resources to be used by teachers in class, in order to personalize learning and connect learning experiences in and out of school [40,41]. In this sense, funds of identity are understood to comprise those people, spaces, things and activities which, for the learners, are the most important and most relevant, and which, ultimately, best define them [42]. They may involve significant people, such as partners or family (social funds of identity), spaces or places, such as a city, a mountain or the sea (geographical funds of identity), institutions such as the Catholic Church or the Muslim religion (institutional funds of identity), interests and activities (identity practices) or cultural artifacts, such as a flag, a mobile phone or a musical instrument (cultural funds of identity) [36].

While family practices are the units of analysis in the funds of knowledge approach, the idea of funds of identity complements this by incorporating the learners, or students, themselves; in particular, by incorporating the resources (knowledge, interests, significant people, institutions, practices, places and spaces) perceived by the student as significant [33]. Another key difference concerns how these funds are identified. Funds of knowledge are identified by means of teachers making ethnographic visits to families, and talking in depth about work experiences, routines and daily life, linguistic practices, and family literacy. In contrast, funds of identity are generated by the learners, who produce artifacts such as drawings, images and videos—tasks that can be used as resources for establishing connections between the curriculum and students' lives [42].

In this regard, merely including cultural references and identities by means of, for example, incorporating the learner's mother tongue, does not automatically produce learning. The mere artifact itself-although it is an epistemic, mediating instrument, and generates, in this case, sense and meaning about oneself-is not, on its own, enough, since superficial views about their own reality, and that of those around them, can appear in these identity artifacts. What is needed is shared pedagogical mediation, capable of guiding learners' interests and identities towards pedagogical and curricular objectives [39].

Within this proposal, then, funds of identity-which are created and manifested through identity artifacts such as drawings, videos, collages, photographs or graphic representations-become the basis for the educational activity, although they do not represent academic learning processes in their own right. To this end, a connection must be sought and formed with the contents or competences involved in the subject of learning; whether this be an author, a topic, a competence, a theory, an intervention 
program, or any aspect related to the theoretical-methodological-practical body of a particular subject or module.

Recently, researchers have used avatars, digital representations of students, along with identifying texts to represent and build students' funds of identity, and thereby promote learning processes in the context of second languages acquisition [43]. In that context, it was suggested that the funds of identity approach is a development of the funds of knowledge approach, and heralds a new phase in the literature regarding this subject, which the author sought to encapsulate with the labels "digital funds of identity" and "funds of knowledge 2.0" [43]. It is in this sense that we adopt the idea of funds of identity 2.0, to link it to the scenario of participatory culture described above (see Figure 1).

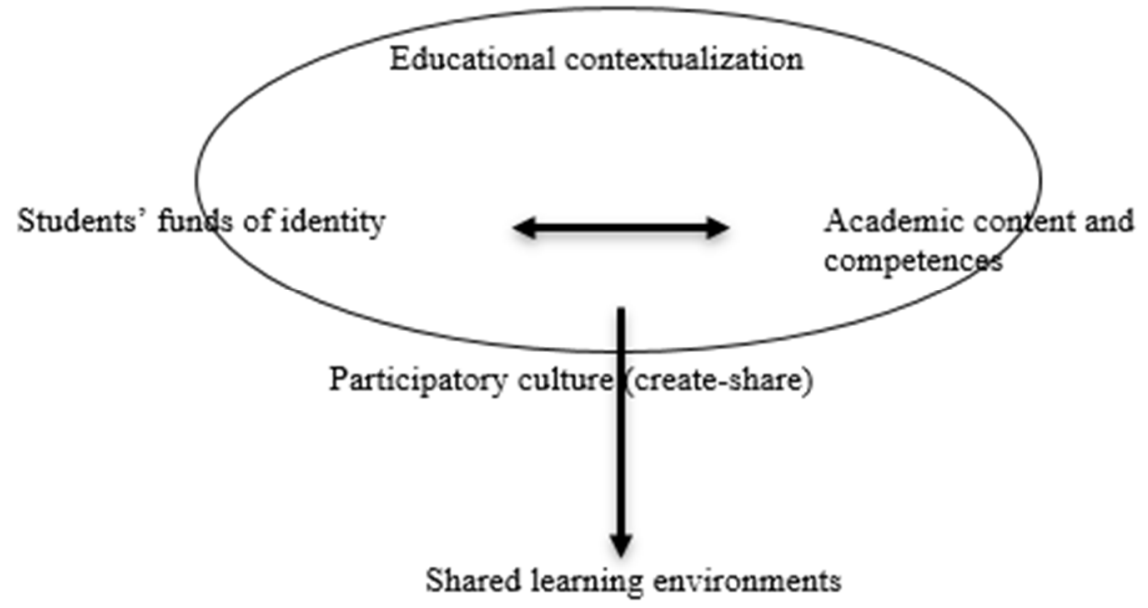

Figure 1. Theoretical model for funds of identity 2.0.

By funds of identity 2.0 we refer to the pedagogical use of students' identities in participatory virtual learning environments. Digital learning spaces, such as Wikis, blogs, multimedia sharing (e.g., a YouTube channel), can be interrelated with offline activities such as academic texts, creating a hybrid learning practice for contextualizing education, that is, for connecting the curriculum to students' personal identities and experiences.

This is a novel contribution to the literature, given that the available research on funds of identity has centered on the design and implementation of physical practices of teaching/learning in primary and secondary school contexts [22,30,32,35-41]. In contrast, we here propose a hybrid design—both physical and online-with university students.

In this regard, the general aim of this paper is to describe the design, implementation process and evaluation of an academic activity in higher education based on the theoretical approach described above. In particular, it describes the phases, characteristics and outcomes of the interactive learning project based on the funds of identity 2.0 approach, within the context of participatory culture.

\section{Materials and Methods}

\subsection{Participants}

A total of 60 university students ranging in age from 20 to 32 years old (average age 21.46 years) took part in the study. They were enrolled in the subject Educational Psychology in the third year of the degree course in psychology in the academic year 2017-2018. More specifically, the activity was implemented from February 2018 to May 2018. Of the group, 92\% were women (55 participants) and $8.3 \%$ were men (5 participants).

Ethical approval for conducting this research was provided by the ethical committee of the University of Girona. All participants took part voluntarily and agreed to sign a document of informed consent giving their permission to publish their identity artifacts, videos and other information resulting from this research. Only in one case did a student not want to make public the video they 
had made in the YouTube channel; the other 59 shared their videos on the YouTube channel created to upload the final result of the activity. For reasons of confidentiality, letters are used to identify the participants (for example, LPG).

\subsection{Instruments}

In order to identify/generate the students' funds of identity (to answer the question "What are my funds of identity?"), we employed an adaptation of the self-portrait drawing technique [44]. The instructions used were: "Depict—by means of a graph, a map, a drawing, a collage, a photograph, a text, or any other resource or medium - what is most significant or most important to you, what best defines you. It may be people, institutions, objects, activities, hobbies, knowledge, ideas, interests, spaces or places that are relevant to you."

To create and share knowledge about a specific content, competence and topic related to the learning subject Educational Psychology, students created and shared several videos. The instructions used were: "You will make a short video (about 2-5 min in length), where you summarize the most significant aspects of the work you have done, and then share it on the YouTube channel "UdG Psicologia-Educació". This video may contain a Power Point presentation, an interview, fieldwork, a mixture of content (texts, photographs), etc., related to a particular author, subject, content, or competence connected to the subject (the author, subject, content and competence selected and linked previously with some of your funds of identity)."

\subsection{Procedure}

Five phases were implemented to connect students' funds of identity and the subject Educational Psychology. Then, the model presented here (see Figure 1) is given practical expression in our proposal for an educational activity developed in five stages. The idea is to apply the notion of participatory culture using students' productions, by linking their identities (interests, significant cultural artifacts, people, institutions, spaces or places, practices or activities) to the contents and competences of the subject or module. These contents may consist of theories or theoretical approaches (the theory of attachment or meaningful learning, for example), key topics (such as technological education or inclusive education) and/or authors (Lev Vygotski or Jerome Bruner, for example). The competences refer to "describing and evaluating different perspectives on the issues or problems they address", or "identifying diversity in cultural and social practices", for example (see Table 1).

\subsection{Data Collection and Analysis}

To collect empirical data for analysis, two instruments were used: the identity artifact described above, and an autoevaluation form in the 5th phase (see Table 1). The empirical data was analyzed using a thematic content analysis to identify themes or patterns of meaning within identity artifacts. In particular, geographical, social, institutional, cultural and practical funds of identity were identified, counting the number of references that appeared in the 60 collected identity artifacts (see Table 2). To identify the specific contents of the learning that students say they have carried out, three categories (themes or patterns of meaning) were created: academic-type learning, technical procedures of production and distribution of content, and attitudinal learning aspects, such as learning strategies, or the conception of onseself as a learner. 
Table 1. Phases of the interactive learning project based on the funds of identity 2.0 approach.

\begin{tabular}{lll}
\hline \multicolumn{1}{c}{ Phase } & \multicolumn{1}{c}{ Instruction } & \multicolumn{1}{c}{$\begin{array}{c}\text { Period } \\
\text { (Length of Time Allocated for the Task) }\end{array}$} \\
\hline 1st phase: What are my & $\begin{array}{l}\text { Depict-by means of a graph, map, drawing, collage, } \\
\text { photograph, text, or any other resource or medium, what is } \\
\text { most significant or most important to you, what best } \\
\text { defines you. It may be people, institutions, objects, } \\
\text { activities, hobbies, knowledge, ideas, interests, spaces or } \\
\text { places that are relevant to you. }\end{array}$ & 1 week \\
Link any of the elements depicted in the first task to \\
a content, topic or competence included in the subject \\
Educational Psychology. These may be topics, authors, \\
competences or contents that are part of the syllabus.
\end{tabular}

Table 2. Typology of funds of identity of participants.

\begin{tabular}{cc}
\hline Types of Funds of Identity & $\begin{array}{c}\text { Number of Times They Appear } \\
\text { in the 60 Identity Artifacts }\end{array}$ \\
\hline Geographical funds of identity (cities, spaces, countries) & 29 \\
Social funds of identity (family, couple, friends) & 121 \\
Cultural funds of identity (physical and symbolic artifacts) & 33 \\
Identity practices (hobbies, activities such as music or sports) & 53 \\
Institutional funds of identity (reference to institutions such as the Church) & 36 \\
\hline
\end{tabular}

\section{Results}

We divide the results into three sections. The first phase is illustrated, consisting of the production of identity artifacts to identify students' funds of identity. Second, the topics chosen by students from their identity funds are described (phases 2, 3 and 4). Finally, the learning acquired is described according to the students' self-assessment (phase 5).

\subsection{Phase 1. Identity Artifacts and Funds of Identity}

In relation to identity artifacts, the variety of resources and formats used stands out, despite the fact that a majority of the students either made a collage (a total of 23 students) or drawings (in 14 of the cases) (see Figure 2), together representing more than half of the students. 


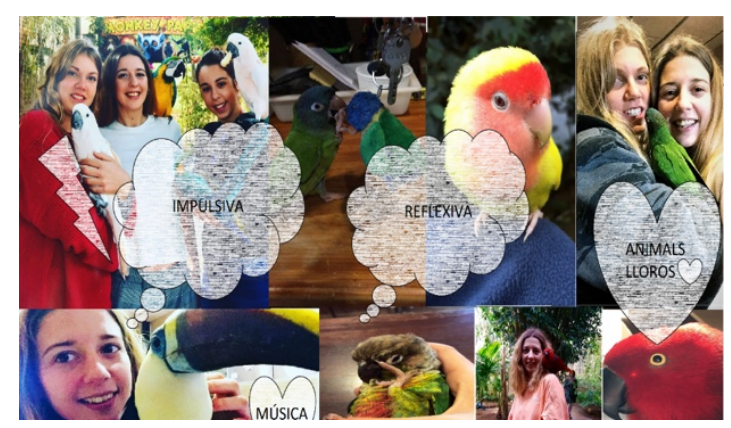

Figure 2. Example of a collage made by BPM.

In the example of the collage shown in Figure 2, words and photographs appear that highlight the most significant elements for BPM. More specifically, these words are: impulsive, thoughtful, animals (parrots) and music (BPM plays the flute and the guitar). We also see significant people, and the activity depicted in the collage is described: "Finally, in the most privileged place, we find the love of animals, especially of the animals in the bird park where I work, which are a source of great enthusiasm and unconditional support in my daily life. Exotic animals are in fact my main passion." (Explanation of the collage given by BPM).

Other means and resources used were significant or representative objects of the person (in the case of six students), the making of a photographic album (also in six students), a text or piece of writing (four students), the making of a comic (two students) and, finally, in five cases, other different identity artifacts: self-description through a word cloud, the making of an avatar, a poster, a song, and lastly, a PowerPoint presentation. In the case of objects, it is worth mentioning that two students used a box in which they placed significant elements (see Figure 3, for example).

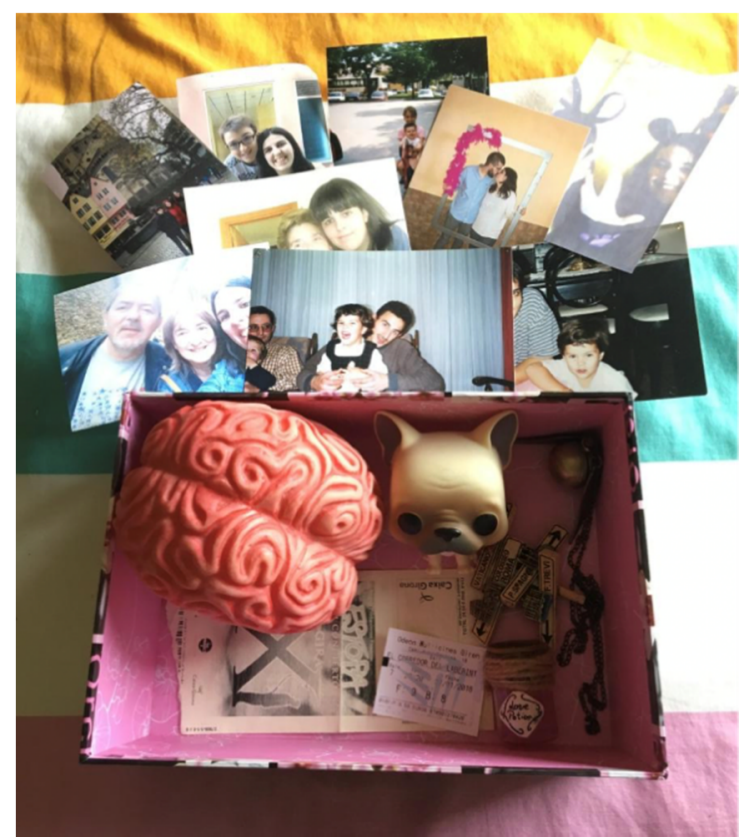

Figure 3. Example of an object as identity artifact (student LPL).

LPL includes, in what she calls a "box of significant objects", different photographs (her boyfriend, friends and family), a representation of her $\mathrm{dog}$, as well as representations of her hobbies: cinema, music, traveling, and neurosciences, symbolized by a brain (see Figure 3).

Regarding the funds of identity identified from the 60 identity artifacts, the importance of funds of social identity is emphasized, in addition to the reference to significant others, including family, 
partners and friends, as well as identity practices, hobbies and activities, such as sports, music, social networks or video games (see Table 2).

\subsection{Phases 2, 3 and 4. Linking of Funds of Identity with the Subject}

During phase 2, described in the procedure section, students connected some of their funds of identity with a topic or content from the subject Educational Psychology. The topics were diverse: family as a developmental context, neuroeducation, coeducation, sports and school performance, fandom as a learning practice and context, the use of ICT for educational purposes, and intercultural education, among many others (see Figure 4). Basically, the connection either comes from the participants' social funds of identity, or from a significant identity practice, for example a job-either current, or the one that the student would like to have in the future. This is the case of BPM (see Figure 2), who says: "As I have represented in my collage, exotic animals, in addition to my work, are my passion, with which I would like to focus on the intervention and reeducation of people with autism using educational activities with animals." In the case of LPL (see Figure 3), the student himself says: "Inside the box, the brain is the most important object, and that is what I will link with the work. I hope my future is connected to neuropsychology. I would like to link education with neuroscience; I have read some articles about neuroeducation and I would like to develop this topic."
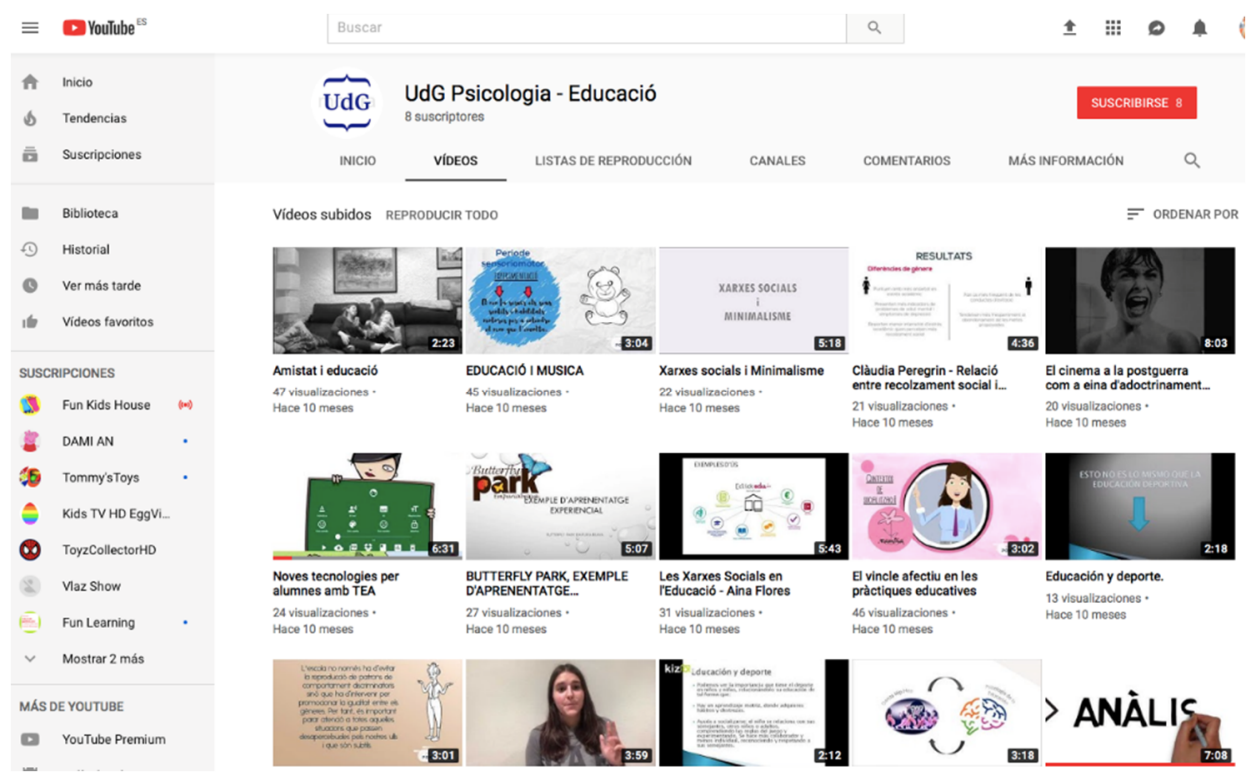

Figure 4. Screenshot of the YouTube channel "UdG Psicologia-Educació" accessible via the link: https://www.youtube.com/channel/UCQzuUhsourEYQq29AGmlqqA/videos.

In Phase 3, the students did the fieldwork. The objective here was to construct knowledge in relation to the theme chosen in Phase 2. To do this, some students carried out interviews with experts. This was the methodology used by 12 of the 60 students. For example, in one case, a student interviewed an expert in emotional intelligence, with the aim of understanding more about the concept, as well as more about educational interventions aimed at fostering emotional intelligence in students (see Figure 5). In another example, with the aim of documenting and illustrating education in leisure time, a student interviewed various monitors from leisure organizations. Another strategy for constructing knowledge and learning in relation to their chosen topic involved a review of articles and books on the topic in question. This was the commonest procedure, chosen by 38 of the 60 students. Finally, in 10 cases, the students opted to carry out small-scale empirical studies. An example of this was a study conducted by one student who recorded and analyzed the effect of a cooperative methodology for learning in scuba-diving classes. In another example, aimed at analyzing the relationships between 
video games and learning, one student created a simple video game for learning about aspects related to World War II. This game was implemented in a classroom, and the learning was then assessed.

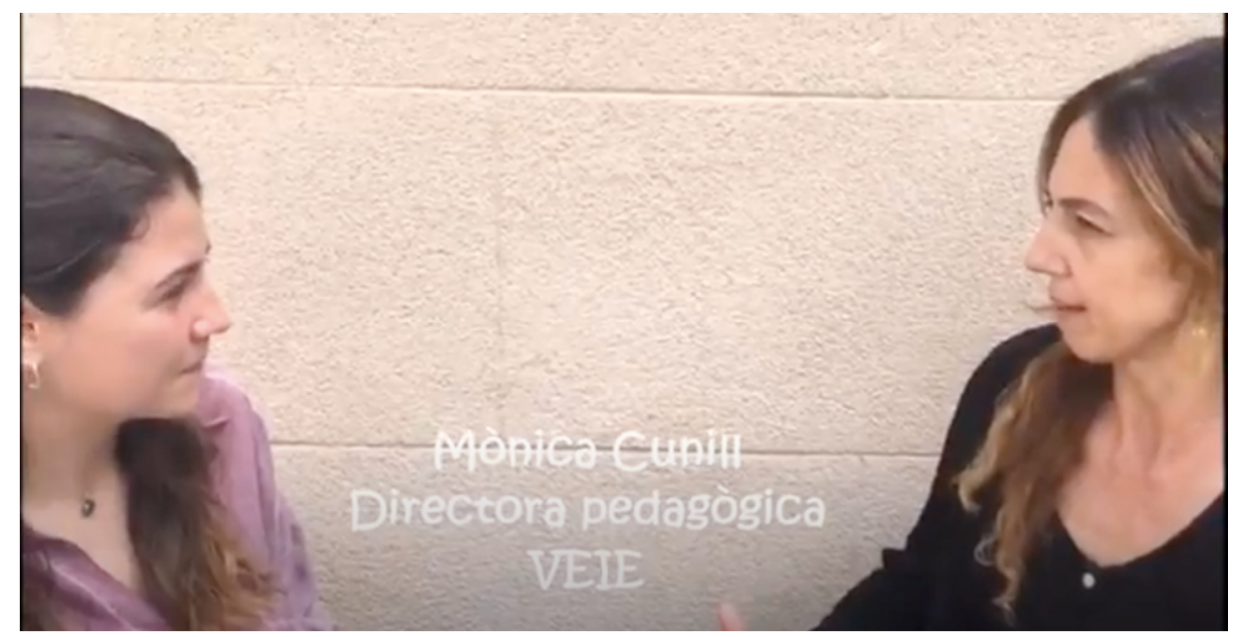

Figure 5. Screenshot of an interview carried out by student with an expert on emotional intelligence.

Subsequently, in Phase 4, each student made a video on the objective of explaining and developing the topic. The videos were uploaded to the YouTube channel created for the project "UdG Psicologia-Educació" (see Figure 5). To comply with this task, the students chose freely from various resources. Specifically, more than half of them (32 out of 60) used PowerPoint presentations, which they made and uploaded to the YouTube channel. A total of 12 others employed other digital tools, such as video editors or story presentation software like Moovly@ and Powtoon $($ C. Finally, in 16 cases, the videos contained the students' own recordings of interviews with experts, experiments carried out, or images that complemented and illustrated the narrative content of the videos.

\subsection{Phase 5. Self-Evaluation and Learning Obtained}

After completing the activity, the 60 students awarded themselves grades, in a self-assessment process, obtaining an average of 1.7 out of 2 , which is equivalent to a high average perceived performance of 8.4 out of $10(\mathrm{~B}+)$.

Regarding the specific content of the learning that students said they had accomplished, the mention of academic-type learning stands out, with 61 references. For example, "I have learned to take into account the different factors that influence children's school performance", (APC); "I have learned various things about neuroscience, and in particular the basics of neuroeducation", (IA); "I have learned to distinguish between intercultural education and multicultural education", (SBM). However, they also frequently mention technical procedures of the production and distribution of content, with a total of 47 references to this effect. This is the case, for example, for BFN, who says, "creating the realization of the video has allowed me to acquire technological skills related to the edition or use of animation programs". In another example: "I had no idea that you could use programs to present information in an engaging way. In my case I used PowToon; it is a very good resource for preparing presentations", (ABT). Finally, we could highlight another category of learning, linked to attitudinal aspects, learning strategies, and even linked to the conception of oneself as a learner, with 31 references. For example: "It has been an effort for me in terms of planning and the capacity to synthesize, which can help me in other learning tasks and situations", (NBF). According to NCB: "I learned the importance of planning; I usually leave everything until the last minute, and when you make a video you have to first write a script, know what you want to explain, how you are going to divide the information, etc. I think I am now a more competent learner, I would say, at least as regards the management of time and the importance of planning." 


\section{Discussion}

The term participatory culture $[11,12,17,19]$, as an object of study, is not strictly linked to the study of how digital devices can improve learning processes, but rather to the analysis of new cultural forms of media convergence, production and participation, as well as forms of social organization and social change [4]. These subjects appear in informal spheres, and can teach us how learning can be improved both inside and outside of formal contexts, as well as in the transformation of society in general [14].

Exploiting these emerging cultures, which are busy creating and distributing knowledge, means offering students opportunities to create and share academic and cultural products that will connect with their passions, interests, competences and prior knowledge-or what we would refer to as the students' funds of identity [36-38,45,46]. Through the creation of identity artifacts [38], the thinking behind funds of knowledge and identity allows us to give practical expression to the concept of participatory culture with pedagogical purposes.

Merely engaging in educational activities based on materials created by the students themselves, and based on their interests, experiences and identities, does not, in itself, demonstrate the existence of participatory culture. However, in the notion of funds of identity 2.0, which we propose here, and in the intervention we have just described, the various elements of participatory culture can be seen. First, there is affiliation in the sense of belonging to the class as a group, in a formal setting, as well as the online community of the YouTube channel "UdG Psicologia-Educació" (see Figure 5). Then there is expression, in the identity artifacts created along with the various recordings uploaded, shared and commented on, via the YouTube channel, and it was in this online space of interaction and exchange that the collaborative work was carried out. Finally, circulation was achieved by sharing the videos, along with the comments and reactions associated with them.

It is within this framework that we implemented a project which contextualizes the contents and competences involved in university subjects, via the creation and dissemination of videos based on the link between funds of identity and the learning subject. The proposed model can be used in any subject, as it is flexible with regard to subject matter. That is, it is a pedagogy that can be easily adapted to any field of university study, and even other contexts, because it is the students themselves who link their funds of identity with a topic, author or content of the subject.

In line with learner-centered, student-centered or child-centered teaching, the starting point is the active role of the learner in processes of teaching and learning [6,25]. However, the main difference is that the notion of funds of identity is broader than that of previous interests and knowledge. In fact, previous interests and knowledge do appear in the identity artifacts, but so do other significant elements, such as other people, other spaces and places, personal projects, institutions and certain cultural artifacts. In other words, the idea of students' identities is more expansive than the simpler notion of interests, which, in the literature on the subject, is often reduced to certain preferences, likes or hobbies that the learner has, or else is described as a cognitive and motivational variable, to describe a certain predisposition to attend to or engage with certain objects and events, and to participate in certain activities over time [47].

Another advantage derived from the proposal presented here is that it supports culturally-sustaining pedagogy [45]. In that regard, the empirical example described here can be considered an educational practice that recognizes, maintains, and uses for pedagogical purposes the identity diversity in the class. In other words, the curriculum is channeled through the references of the lived experiences of students. It reinforces the inclusive pedagogies based on the recognition of the living cultures and practices of students, allowing these cultural and personal references to be maintained and sustained. Finally, incorporating meaningful students' experiences allows us to connect learning in and out of formal institutions (school, university) [45]. Identity artifacts mobilize personal experiences (students' funds of identity). By incorporating them into university practice, meaningful and contextualized lessons can be developed, connecting learning and experiences in and out of university. 
However, it has the disadvantage that the chosen concept or topic is studied in depth, perhaps leaving out other aspects of the curriculum that could be covered. It is therefore recommended to complement this pedagogy - which is closer to processes of personalization of learning, in which the learner takes a leading role and responsibility in the processes of choosing and linking their interests and needs, and linking them with the contents and curricular themes [46] —with others that enable us to expand the learning of content, competences and authors associated with a particular university subject.

Further implementation of the concept of funds of identity 2.0 is needed in order to determine both its potential, and its disadvantages or limitations, when it comes to generating learning processes. In this respect, future studies are required that document other experiences related to the methodology proposed here. Some of the issues are: What advantages are derived from the proposal presented here? What are its limitations? What improvements can be made? Does the proposed approach allow learning experiences to be connected inside and outside of the formal contexts of teaching and learning? Does the fact that students learned the content and the relevant technological skills mean that a participatory culture was created, or nurtured? In short: How does the idea of funds of identity 2.0, and the associated methodology, contribute to teaching and learning processes in formal educational contexts? To resolve these issues, it is necessary first to design more activities like those proposed here, and then evaluate their impact (for instance, with a quasi-experimental design: pre and post-test). The results obtained in this study allow us to suggest that learning is obtained on at least two levels: the theoretical-academic and the procedural, either by increasing competency in the creation and presentation of content through digital media, or by the development of learning strategies. However, the impact on student motivation and involvement, which we consider positive, as well as the potential long-term impact, has not been explored. Longitudinal studies would be required to document, a posteriori, the learning that students claim they have accomplished, as well as the incorporation of other measures and sources to evaluate them, beyond the conclusions of the learners themselves, which we consider to be another limitation of the study presented here. With regard to the students, their lived experiences within the intervention should be more thoroughly and carefully explored in future studies. Another area that should be addressed concerns the potential connections between the funds of identity revealed in students' identity artifacts and the learning they achieved during Phases 3 and 4 of the project. Focusing the analysis on a few cases would allow us to describe this process in more depth, by obtaining, for example, more data on the linking process (when choosing the topics from particular funds of identity) and on the learning impact of the different phases described in Table 1.

Author Contributions: Conceptualization, M.E.-G.; methodology, M.P.; formal analysis, I.G.-C.; investigation, M.P.; writing—original draft preparation, M.E.-G.; writing—review and editing, P.M.-B. All authors have read and agreed to the published version of the manuscript.

Funding: This research was funded by the Spanish Ministry of Economy, Industry and Competitiveness (MINECO), the Spanish State Research Agency (AEI) and the European Regional Development Funds (European Union), gran number EDU2017-83363-R.

Conflicts of Interest: The authors declare no conflict of interest. The funders had no role in the design of the study; in the collection, analysis, or interpretation of data; in the writing of the manuscript, or in the decision to publish the results.

\section{References}

1. Barron, B. Interest and self-sustained learning as catalysts of development: A learning ecology perspective. Hum. Dev. 2006, 49, 193-224. [CrossRef]

2. Erstad, O. Digital Learning Lives; Peter Lang Publishing: New York, NY, USA, 2013.

3. Esteban-Guitart, M.; Coll, C.; Penuel, B. Learning across settings and time in the Digital age. Digit. Educ. Rev. 2018, 33, 1-16. [CrossRef]

4. Gee, J.P.; Esteban-Guitart, M. Designing for deep learning in the context of digital and social media. Comun. Media Educ. Res. J. 2019, 58, 9-18. [CrossRef] 
5. Liin, G. Sustainability in lifelong learning: Learners' perceptions from a Turkish distance language education context. Sustainability 2019, 11, 5284. [CrossRef]

6. Tomé, M.; Herrera, L.; Lozano, S. Teachers' opinions on the use of personal learning environments for intercultural competence. Sustainability 2019, 11, 4475. [CrossRef]

7. Bower, M. Deriving a typology of Web 2.0 learning technologies. Brit. J. Educ. Technol. 2015, 47, 763-777. [CrossRef]

8. Chien, Y.H. Technology-enhanced learning: An optimal CPS learning application. Sustainability 2019, 11, 4415. [CrossRef]

9. Churchill, D. Educational applications of Web 2.0: Using blogs to support teaching and learning. Brit. J. Educ. Technol. 2009, 40, 179-183. [CrossRef]

10. González-Martínez, J.; Serrat-Sellabona, E.; Estebanell-Minguell, M.; Rostan-Sánchez, C.; Esteban-Guitart, M. Sobre el concepto de alfabetización transmedia en el ámbito educativo: Una revisión de la literatura. Comun. Soc. 2018, 33, 15-40. [CrossRef]

11. Jenkins, H. Convergence Culture: Where Old and New Media Collide; New York University Press: New York, NY, USA, 2006.

12. Jenkins, H. Confronting the Challenges of Participatory Culture: Media Education for the 21st Century; MIT Press: Cambridge, UK, 2009.

13. Martín-García, R.; López-Martin, C.; Arguedas-Sanz, R. Collaborative learning communities for sustainable employment through visual tools. Sustainability 2020, 12, 2569. [CrossRef]

14. Gee, J.P. Teaching, Learning, Literacy in Our High-Risk, High-Tech World; Teachers College Press: New York, NY, USA, 2017.

15. Esteban-Guitart, M.; Serra, J.M.; Vila, I. Informationalism and informalization of learnings in 21st century: A qualitative study on meaningful learning experiences. Soc. Educ. Hist. 2017, 6, 1-25. [CrossRef]

16. González-Patiño, J.; Esteban-Guitart, M. Some of the Challenges and Experiences of Formal Education in a Mobile-Centric Society. Digit. Educ. Rev. 2014, 15, 64-96. [CrossRef]

17. Jenkins, H.; Ito, M.; Boyd, D. Participatory Culture in a Networked Era. A Conversation on Youth, Learning, Commerce and Politics; Polity Press: Cambridge, UK, 2016.

18. Ito, M.; Martin, C.; Pfister, R.C.; Rafalow, M.H.; Salen, K.; Wortman, A. Affinity Online: How Connection and Shared Interest Fuel Learning; New York University Press: New York, NY, USA, 2018.

19. Jenkins, H. Participatory Culture. Interviews; Polity Press: Cambridge, UK, 2019.

20. Lenhardt, A.; Purcell, K.; Smith, A.; Zickuhr, K. Social Media E Mobile Internet Use among Teens and Young Adults; Pew Internet \& American Life Project: Washington, DC, USA, 2010.

21. González, N.; Moll, L.; Amanti, C. Funds of Knowledge: Theorizing Practices in Households, Communities, and Classrooms; Lawrence Erlbaum Associates: Mahwah, NJ, USA, 2005; pp. 1-307.

22. Moll, L. Vygotsky and Education; Routledge: New York, NY, USA, 2014.

23. Moll, L. Elaborating funds of knowledge: Community-oriented practices in international contexts. Lit. Res. 2019, 67, 12-18. [CrossRef]

24. Moll, L. Hacia un Curriculum Cultural. La Vigencia de Vygotski en la Educación; Álvarez, A., Ed.; Infancia y Aprendizaje: Madrid, Spain, 1997; Chapter 3; pp. 39-53.

25. Tharp, R.G. Four hundred years of evidence: Culture, Pedagogy, and Native America. J. Am. Ind. Educ. 2006, 45, 6-25.

26. Yamauchi, L. Making school relevant for at-risk students: The Wai'anae High School Hawaiian Studies Program. J. Educ. Stud. Places At-Risk 2003, 8, 379-390. [CrossRef]

27. Valencia, R.R. The Evolution of Deficit Thinking: Educational Thought and Practice; Routledge: New York, NY, USA, 1997; pp. 1-287.

28. McIntyre, E.; Rosebery, A.; González, N. Classroom Diversity: Connecting Curricula to Students' Lives; Heinemann: Portsmouth, MH, USA, 2001; pp. 1-134.

29. Esteban-Guitart, M.; Serra, J.M.; Llopart, M. The role of the study group in the founds of knowledge approach. Mind Cult. Act. 2018, 25, 216-228. [CrossRef]

30. Hogg, L. Funds of knowledge: An investigation of coherence within the literature. Teach. Teach. Educ. 2011, 27, 666-677. [CrossRef]

31. Llopart, M.; Esteban-Guitart, M. Funds of knowledge in 21st century societies: Inclusive educational practices for under-represented students: A literatura review. J. Curric. Stud. 2018, 50, 145-161. [CrossRef] 
32. Jovés, P.; Siqués, C.; Esteban-Guitart, M. The incorporation of funds of knowledge and funds of identity of students and their families into educational practice: A case study from Catalonia, Spain. Teach. Teach. Educ. 2015, 49, 68-77. [CrossRef]

33. González, N.; Wyman, L.; O'Connor, B. The past, present, and future of "Funds of knowledge". In A Companion to the Anthropology of Education; Levinson, B.A., Pollock, M., Eds.; Wiley-Blackwell: Hoboken, NJ, USA, 2011; pp. 479-494.

34. Llopart, M.; Serra, J.M.; Esteban-Guitart, M. Teachers' perceptions of the benefits, limitations, and areas for improvement of the funds of knowledge approach: A qualitative study. Teach. Teach. 2018, 24, 571-583. [CrossRef]

35. Esteban-Guitart, M. Towards a multimethodological approach to identification of funds of identity, small stories and master narratives. Narrat. Inq. 2012, 22, 173-180. [CrossRef]

36. Esteban-Guitart, M. Funds of Identity. Connecting Meaningful Learning Experiences in and Out of School; Cambridge University Press: New York, NY, USA, 2016; pp. 1-123.

37. Esteban-Guitart, M.; Moll, L.C. Funds of identity: A new concept based on the funds of knowledge approach. Cult. Psychol. 2014, 20, 31-48. [CrossRef]

38. Saubich, X.; Esteban-Guitart, M. Bringing funds of family knowledge to school: The living Morocco project. REMIE Multidiscip. J. Educ. Res. 2011, 1, 57-81. [CrossRef]

39. Subero, D.; Llopart, M.; Siqués, C.; Esteban-Guitart, M. The mediation of teaching and learning processes through identity artifacts: A Vygotskian perspective. Oxf. Rev. Educ. 2018, 44, 156-170. [CrossRef]

40. Llopart, M.; Esteban-Guitart, M. Strategies and resources for contextualizing the curriculum based on the funds of knowledge approach: A literature review. Aust. Educ. Res. 2017, 44, 255-274. [CrossRef]

41. Subero, D.; Vujasinovic, E.; Esteban-Guitart, M. Mobilizing funds of identity in and out of school. Camb. J. Educ. 2017, 47, 247-263. [CrossRef]

42. Esteban-Guitart, M.; Moll, L. Lived Experiences, Funds of Identity and Education. Cult. Psychol. 2014, 20, 70-81. [CrossRef]

43. Poole, A. Funds of knowledge 2.0: Towards digital funds of identity. Learn. Cult. Soc. Interact. 2017, 13, 50-59. [CrossRef]

44. Bagnoli, A. Beyond the standard interview: The use of graphic elicitation and arts-based methods. Qual. Res. 2009, 9, 547-570. [CrossRef]

45. Esteban-Guitart, M.; Lalueza, J.L.; Zhang-Yu, C.; Llopart, M. Sustaining students' cultures and identities: A qualitative study based on the funds of knowledge and identity approaches. Sustainability 2019, 11, 3400. [CrossRef]

46. Esteban-Guitart, M.; Gee, J.P. "Inside the head and out in the world." An approach to deep teaching and learning. Multidiscip. J. Educ. Res. 2020, 10, 1-25. [CrossRef]

47. Renninger, K.A.; Hidi, S.W. To level the playing field, develop interest. Policy Insights Behav. Brain Sci. 2020, 7, 10-18. [CrossRef]

(C) 2020 by the authors. Licensee MDPI, Basel, Switzerland. This article is an open access article distributed under the terms and conditions of the Creative Commons Attribution (CC BY) license (http://creativecommons.org/licenses/by/4.0/). 